\title{
(6) OPEN ACCESS \\ Safety netting versus overtreatment in paediatrics: viral infection or incomplete Kawasaki disease?
}

\author{
Jennifer Michelle Charlesworth, ${ }^{1}$ Bernadette Power, ${ }^{2}$ Edina Moylett ${ }^{3}$
}

\begin{abstract}
${ }^{1}$ Department of Medicine, National University of IrelandGalway, Galway, Ireland ${ }^{2}$ Department of Paediatrics, Letterkenny General Hospital, Letterkenny, Donegal, Ireland ${ }^{3}$ Department of Paediatrics, University College Hospital Galway, Galway, Ireland
\end{abstract}

\section{Correspondence to Dr Jennifer \\ Michelle Charlesworth, charlesworth.jennifer@gmail. com}

Accepted 17 October 2017

To cite: Charlesworth JM, Power B, Moylett E. BMJ Case Rep Published Online First: [please include Day Month Year]. doi:10.1136/bcr-2017222323

\section{SUMMARY}

Kawasaki disease (KD) is the most common systemic vasculitis of childhood. The following presentation of a 4-year-old Irish boy referred to a secondary care paediatric service from the community with prolonged fever, oral mucous membrane changes and painless blistering lesions of the hands and feet in the presence of elevated inflammatory markers serves as an opportunity to discuss the diagnostic criteria and treatment for KD and incomplete $K D$, an often missed diagnosis with significant paediatric morbidity outside an academic paediatric centre.

\section{BACKGROUND}

Kawasaki disease (KD) is a systemic vasculitis of childhood identified initially in Japan in the 1960s. ${ }^{1}$ Incidence of KD in children aged 5 and under varies worldwide from 4.9 per 100000 children in Denmark to 211 or more in Japan or those of Japanese descent. ${ }^{2-4}$ The exact aetiology of KD remains unknown. ${ }^{5}$ It is of major concern as 10\%-25\% of confirmed untreated cases may develop coronary aneurysms and have increased risk of myocardial ischaemia, infarction and sudden death. ${ }^{36}$ A subset of incomplete cases who do not meet all established criteria for $\mathrm{KD}$ are also recognised in the literature to be at equivalent risk of serious sequelae and are more likely to go untreated. ${ }^{67}$ This recognition failure leading to treatment delay increases the risk of immediate and delayed coronary artery aneurysm, which is the leading cause of acquired heart disease in children. ${ }^{38}$ The following case of intermittent prolonged fever and rash in a 4-year-old boy illustrates the difficulty clinicians face to treat prophylactically when a common presentation of upper respiratory tract infection partially fulfils the diagnostic criteria for a more severe illness such as incomplete KD (iKD).

\section{CASE PRESENTATION History}

A 4-year-old white Irish fraternal twin boy was referred to the paediatric service from the community with a history of :

- 3 weeks of recurrent tonsillitis, coryza and dry cough for ;

- 2 weeks of painless blistering lesions on hands, feet and mouth (with or without fever) ;

- 4 days of documented relapsing and remitting fever $39^{\circ} \mathrm{C}$ in the setting of decreased oral intake.
Of note, his twin sister was hospitalised with similar symptoms for 24 hours prior to the patient and then discharged home. Neither child had vomiting, diarrhoea, meningeal signs, mucositis or strawberry tongue during illness.

\section{Prior medical history}

The patient was well prior to admission, up to date with all vaccinations, had no allergies and took no regular medications other than paracetamol and amoxicillin prescribed in the community.

His obstetric, birth history and neonatal course was unremarkable except for an in vitro fertilisation assisted twin pregnancy and C-section for breech presentation at term. His development to date is normal.

Examination at admission was of an afebrile, alert, oriented 4-year-old boy in no acute distress. He weighed $14.7 \mathrm{~kg}$. All other vital signs were within normal parameters for a child of his age.

Examination of the respiratory, cardiovascular and gastrointestinal systems was unremarkable. Examination of the eyes, ears, nose and throat revealed no bulbar conjunctival injection, a right erythematous tympanic membrane, erythematous, congested nasal mucosa and erythematous, inflamed pharyngeal tonsils without exudate.

Musculoskeletal survey and review of systems were also unremarkable.

Intermittent irritability, lethargy and fevers $\left(38^{\circ} \mathrm{C}-39^{\circ} \mathrm{C}\right)$ continued for 24 hours after admission. A faint abdominal exanthem and bilateral uniquely cervical lymphadenopathy in addition to erythematous oral mucosa and scattered lower respiratory crepitations were noted at this time.

\section{INVESTIGATIONS}

Blood work revealed a neutrophil leucocytosis with elevated inflammatory markers (C reactive protein (CRP) $44.32 \mathrm{mg} / \mathrm{L}$ with erythrocyte sedimentation rate (ESR) of $60 \mathrm{~mm} /$ hour). Platelets were normal. The patient was not anaemic, but his serum albumin was on the low side of normal. His fibrinogen was mildly elevated and red blood cell count mildly decreased. All other blood work and urine culture were normal.

\section{DIFFERENTIAL DIAGNOSIS}

1. Viral upper respiratory tract infection

2. Human adenovirus ${ }^{9}$

3. iKD

4. Juvenile idiopathic arthritis 
5. Acute streptococcal and staphylococcal infections (staphylococcal scalded skin syndrome)

6. Drug hypersensitivity reactions

7. Toxic epidermal necrolysis (aka Steven-Johnston syndrome) ${ }^{10}$

\section{TREATMENT, OUTCOME AND FOLLOW-UP}

In consultation with paediatric infectious disease specialists, the team treated the patient prophylactically with $2 \mathrm{~g} / \mathrm{kg}$ intravenous immunoglobulin (IVIG) for iKD in combination with continued antibiotics (clarithromycin). Laboratory trends including leucocytosis and a low normal albumin in the setting of prolonged spiking fevers in a 4-year-old boy in a facility without on-site paediatric echocardiography $(\mathrm{ECHO})$ capability led to the decision to treat. While this does not meet supplemental laboratory criteria in the new 2017 guidelines, ${ }^{4}$ the rationale for this decision was that the consequences of missing $\mathrm{iKD}$ were thought to be possibly catastrophic in this young child compared with the risks associated with IVIG treatment in the setting of ongoing antibiotics (eg, small risk of aseptic meningitis, haemolytic anaemia). In essence, this is safety netting. In the face of diagnostic uncertainty, the clinician should make the safest decision (aka minimising harm and maximising benefit) while avoiding overtreatment. As there is a known risk of Reye's syndrome with aspirin in an infectious febrile child and thus irreversible neurological sequelae with an unknown treatment benefit, experts initially withheld aspirin. ${ }^{5}$ Treatment was well tolerated by the patient.

The patient was scheduled for cardiology review by paediatric cardiology consultant clinic which occurs biannually and happened to coincide with the patient's discharge date 3 days postadmission. Review at this time revealed possible mild left ventricular hypertrophy on ECG without additional significant changes. Bedside ECHO demonstrated normal coronary arteries and no left ventricular dilation. Findings could not rule out iKD. Paediatric cardiology added a maintenance dose of aspirin $50 \mathrm{mg}$ $(3 \mathrm{mg} / \mathrm{kg}$ ) by mouth daily for easy dosing as the patient was no longer febrile and scheduled the patient for outpatient repeat echocardiography at a tertiary centre in early January 2015 due to risk of late forming coronary aneurysm.

\section{DISCUSSION \\ Diagnosis}

Upper respiratory tract infection coincides with many cases of KD. 91112 The postulated viral aetiology in genetically susceptible patients means that many features of KD are non-specific indicators of inflammation which could be viral or bacterial in origin. ${ }^{24}$ Given the prehospital course, it was unlikely on admission that the patient had an infection of bacterial origin as he had been given three courses of antibiotics that would cover relevant pathogens. The absence of joint involvement make juvenile idiopathic arthritis a less likely differential. ${ }^{2} 413$ While drug hypersensitivity reactions are always possible, the presentation and lack of mucocutaneous findings, along with the number and type of drugs employed and duration of illness, argue against such differentials. ${ }^{14}$ As viral serology, cultures and nucleic acid antigen testing were not available, a viral cause cannot be ruled out with certainty and thus remains the most likely alternative to $\mathrm{iKD} .{ }^{15}$ Since $\mathrm{iKD}$ can only be definitively confirmed on the basis of pathological echocardiography findings which may have been prevented through pre-emptive treatment, it is impossible to be certain to the exact aetiology of this child's illness. Given the risks of treatment outlined briefly above and the discussion below, it is important to examine the rationale for this common treatment dilemma. ${ }^{12}$

\section{KD and incomplete Kawasaki diagnosis}

$\mathrm{KD}$ is a clinical diagnosis based on prolonged fever of 5 days or more with four of the five principal features including (1) bilateral bulbar conjunctival injection, (2) oral mucous membrane changes including injected or fissured lips, injected pharynx or strawberry tongue, (3) peripheral extremity changes including erythema of palms or soles, oedema of hands or feet (acute phase) and periungual desquamation, (4) polymorphous rash and (5) cervical lymphadenopathy (at least one lymph node $>1.5 \mathrm{~cm}$ in diameter). ${ }^{31112}$

The clinical course of KD can be divided into three distinct phases: acute, subacute and convalescent. If possible, it is best to make a diagnosis of KD within 10 days of the onset of illness to prevent coronary sequelae. ${ }^{10}$ As principal features often do not usually coincide temporally at presentation, recognition of KD can be very challenging. ${ }^{2-48}$

$\mathrm{iKD}$ is even more difficult to recognise definitively for any clinician and is a diagnosis of exclusion confirmed often retrospectively on the basis of coronary sequelae. ${ }^{16}$ However, given the severity of complications, it should be considered in any child with prolonged unexplained fever. ${ }^{11} 1217$

No laboratory test is pathognomonic for iKD. Findings consistent with iKD include elevated CRP $\geq 3 \mathrm{mg} / \mathrm{L}$ or ESR $>40 \mathrm{~mm} /$ hour. Other supportive findings include: a white cell cell count of more than $15 \times 10^{9}$ cells/L (neutrophil leucocytosis), normocytic, normochromic anaemia for age, platelet count of more than $450 \times 10^{9}$ cells/L after 7 days of illness, sterile (non-neutrophil) pyuria, elevation of serum aspartate aminotransferase (more than 50 units/L) and serum albumin $\leq 30 \mathrm{~g} / \mathrm{L} .^{2411} 12$

The American Heart Association (AHA) algorithm ${ }^{24}$ for evaluation of suspected $\mathrm{iKD}$ provides a framework for risk stratification to inform clinicians' decision to treat prophylactically. The case outlined had adequate clinical features to entertain a diagnosis of $\mathrm{iKD}$.

Delayed diagnosis of iKD can have profound morbidity. ${ }^{15}$ In the presence of risk factors, up to $25 \%$ of Europeans can develop both early and late cardiac lesions. ${ }^{38}$ In tertiary care centres where initial paediatric echocardiography is available, the presence of echogenic lesions is critical in the decision to treat in the presence of elevated inflammatory markers. Practitioners at secondary care facilities, without access to paediatric echocardiography, face more diagnostic uncertainty. The dilemma to treat or not when algorithms developed at academic centres are predicted on technology or skills not ubiquitously available is not helpful to clinicians in these scenarios resulting in the common practice of safety netting (taking the path where the benefits outweigh the risks); however, abject overtreatment should be avoided. ${ }^{12}$

\section{Treatment of suspected iKD}

Hospitalisation and IVIG $2 \mathrm{~g} / \mathrm{kg}$ in a single infusion within the first 7 days of symptoms have been shown to reduce the prevalence of coronary artery abnormalities. Therapy remains effective up to 10 days for clinical onset preventing new coronary abnormalities but does not treat pre-existing aneurysms or plaques. ${ }^{12}{ }^{1}$ However, risks such as haemolytic anaemia, aseptic meningitis, infection with bloodborne pathogens from human plasma products or Reye's syndrome associated with aspirin administration are infrequent side effects. ${ }^{10} 121$

In this case, while aspirin was withheld initially due to risk of irreversible harms in the setting of unknown benefit, paediatric cardiology did prescribe low-dose aspirin within the $1-5 \mathrm{mg} / \mathrm{kg} /$ day for the 4 weeks prior to repeat review for delayed coronary 
artery lesions. ${ }^{8}{ }^{12}$ Of note, the child was afebrile for a significant period when given aspirin diminishing the theoretical risk of Reye's syndrome. ${ }^{1}$

While the current recommendation is that all patients who have received treatment should be re-evaluated within 2-6 weeks of baseline echocardiogram, further follow-up may be unrealistic. If no changes are seen initially or in the follow-up echocardiogram, further echocardiography is usually unnecessary, ${ }^{24}$ as are activity restrictions or medications beyond 3 months after the initial illness. ${ }^{10} 12$

\section{CONCLUSION}

This case of prolonged fever with features of iKD in a 4-year-old boy has three important learning points: (1) A review of the diagnostic criteria of KD and $\mathrm{KKD}$; (2) the recent AHA treatment algorithms and their limitations in under-resourced or rural areas, in addition to (3) a worked example of the rationale clinicians employ when safety netting in the context of diagnostic uncertainty.

\section{Learning points}

- Kawasaki disease (KD) is the most common systematic vasculitis of childhood with significant paediatric morbidity.

- Diagnosis of incomplete KD (iKD) is more difficult than its traditional counterpart but should not be missed as these children are at similar risk for serious cardiac sequelae.

- There are algorithms to assist with the diagnosis of KD and iKD but they may need to be adapted and used with judicious clinical judgement outside an academic centre when paediatric echocardiography is not available.

- Clinicians must balance the risks and benefits of prophylactic treatment for suspected KD or iKD in context of clinical suspicion in the setting of significant morbidity associated with long-term cardiac sequelae.

Contributors $\mathrm{JMC}$ and BP contributed to the acquisition and interpretation of data for the work; JMC and EM assisted with drafting the work or revising the manuscript critically for important intellectual content. JMC, BP and EM had final approval of the version to be published and are in agreement to be accountable for all aspects of the work in ensuring that questions related to the accuracy or integrity of any part of the work are appropriately investigated and resolved.

Competing interests None declared.

Patient consent Obtained.

Provenance and peer review Not commissioned; externally peer reviewed.
Open Access This is an Open Access article distributed in accordance with the Creative Commons Attribution Non Commercial (CC BY-NC 4.0) license, which permits others to distribute, remix, adapt, build upon this work non-commercially, and license their derivative works on different terms, provided the original work is properly cited and the use is non-commercial. See: http://creativecommons.org/ licenses/by-nc/4.0/

(C) BMJ Publishing Group Ltd (unless otherwise stated in the text of the article) 2017. All rights reserved. No commercial use is permitted unless otherwise expressly granted.

\section{REFERENCES}

1 Bajolle F, Laux D. [Kawasaki disease: what you need to know]. Arch Pediatr 2012;19:1264-8.

2 Newburger JW, Takahashi M, Gerber MA, et al. Diagnosis, treatment, and long-term management of Kawasaki disease: a statement for health professionals from the committee on rheumatic fever, endocarditis and kawasaki disease, council on cardiovascular disease in the young, American heart association. Circulation 2004:110:2747-71.

3 Patel A, Holman RC, Callinan LS, et al. Evaluation of clinical characteristics of Kawasaki syndrome and risk factors for coronary artery abnormalities among children in Denmark. Acta Paediatr 2013;102:385-90.

4 McCrindle BW, Rowley AH, Newburger JW, et al. Diagnosis, treatment, and long-term management of kawasaki disease: A scientific statement for health professionals from the American heart association. Circulation 2017;135:e927-e999.

5 Newburger JW, Takahashi M, Gerber MA, et al. Diagnosis, treatment, and long-term management of Kawasaki disease: a statement for health professionals from the committee on rheumatic fever, endocarditis, and Kawasaki disease, council on cardiovascular disease in the Young, American heart association. Pediatrics 2004:114:1708-33.

6 Muniz JC, Dummer K, Gauvreau K, et al. Coronary artery dimensions in febrile children without Kawasaki disease. Circ Cardiovasc Imaging 2013;6:239-44.

7. Dogra S, Gehlot A, Suri D, et al. Incomplete Kawasaki disease followed by systemic onset juvenile idiopathic arthritis- the diagnostic dilemma. Indian J Pediatr 2013;80:783-5.

8 Holve TJ, Patel A, Chau Q, et al. Long-term cardiovascular outcomes in survivors of Kawasaki disease. Pediatrics 2014;133:e305-e311.

9 Jaggi P, Kajon AE, Mejias A, et al. Human adenovirus infection in Kawasaki disease: a confounding bystander? Clin Infect Dis 2013;56:58-64.

10 Bayers S, Shulman ST, Paller AS. Kawasaki disease: part I. Diagnosis, clinical features, and pathogenesis. J Am Acad Dermatol 2013;69:501.e1-11-quiz 511-2.

11 Sánchez-Manubens J, Bou R, Anton J. Diagnosis and classification of Kawasaki disease. J Autoimmun 2014;48-49:113-7.

12 Sundel R. Incomplete (atypical) Kawasaki disease. In: MKlein Gitelman, Kaplan SL, Waltham MA: UpToDate, 2014. UpToDate.

13 Minich LL, Sleeper LA, Atz AM, et al. Delayed diagnosis of Kawasaki disease: what are the risk factors? Pediatrics 2007;120:e1434-e1440.

14. Nirken MH, High WA, Roujeau J-C. Stevens-Johnson syndrome and toxic epidermal necrolysis: Pathogenesis, clinical manifestations, and diagnosis. In: Adkinson NFJ, Levy ML, eds. UpToDate. Waltham MA: UpToDate, 2017.

15 Miller MM, Miller AH. Incomplete Kawasaki disease. Am J Emerg Med 2013;31:894 e5-894.e7.

16 Giannouli G, Tzoumaka-Bakoula C, Kopsidas I, et al. Epidemiology and risk factors for coronary artery abnormalities in children with complete and incomplete Kawasaki disease during a 10-year period. Pediatr Cardiol 2013;34:1476-81.

17 Puri V, Kanitkar M. Atypical Kawasaki disease. Indian J Pediatr 2013;80:267-8.

Copyright 2017 BMJ Publishing Group. All rights reserved. For permission to reuse any of this content visit

http://group.bmj.com/group/rights-licensing/permissions.

BMJ Case Report Fellows may re-use this article for personal use and teaching without any further permission.

Become a Fellow of BMJ Case Reports today and you can:

- Submit as many cases as you like

- Enjoy fast sympathetic peer review and rapid publication of accepted articles

- Access all the published articles

- Re-use any of the published material for personal use and teaching without further permission

For information on Institutional Fellowships contact consortiasales@bmjgroup.com

Visit casereports.bmj.com for more articles like this and to become a Fellow 